\title{
GLL
}

$00=0$ Geomatics, Landmanagement and Landscape No. $1 \cdot 2020,163-186$

\section{INVENTORYING OF POWER NETWORK USING DETECTION TECHNIQUES}

\author{
Izabela Piech, Tadeusz Żaba, Piotr Bordzoń
}

\section{Summary}

The dynamic development of digital technology allows for fast processing of geospatial information for military and civilian applications. Updating geospatial information is an important source of development for today's economy, based on the freedom of access to databases, and obtaining data using images in different ranges of the electromagnetic spectrum is a comprehensive solution for spatial analysis. Dissemination of research on image acquisition and image processing allows placing sensors at different heights above the Earth's surface [Dąbrowski et al. 2010].

Technological progress allows greater flexibility in the implementation of commissions that enable, over time, obtaining data in an increasingly economical way. An example of technological optimization is the UAV - the unmanned aerial vehicle - technique, which makes it possible to compete with traditional imaging tasks using aerial photographs [Bareth et al. 2015]. Remote sensing applications are becoming more and more common. This is due to the increase in the capacity of photosensitive matrices, which translates into an increase in image resolution. Due to the tendency towards improvement, better image quality, and increasingly sophisticated algorithms for multispectral image analysis, remote sensing applications will constitute an increasing range of services.

The factor favouring the satellite technique is the occurrence of continuous shooting in a short time interval, which affects the popularization of this technique due to the gathering and updating of the collection.

By using various techniques, a quantitative and qualitative analysis will be made, coupled with an assessment of the accuracy of the location of objects, costs and efficiency for each method. Remote sensing is based on the classification of objects. Classes represent the respective values from the intervals, in which different wavelengths interact with the object through reflection, absorption or transmission.

\section{Keywords}

GIS • spectral channels • classification • WORLDVIEW-3 • GSD • NIIRS

\section{Introduction}

The main assumption of the publication was the effective inventorying of LV towers and overhead sections using various photogrammetric and remote sensing techniques: 
satellite imaging, aerial photographs and data obtained from unmanned aerial vehicles. Identification sets include: LV towers and sections. The set of attributes include: tower type, tower function, tower design, network function, wiring system, overhead wire type. The identification was carried out by remote sensing using multispectral and panchromatic images. Specialized remote sensing and photogrammetric software applications were used for this purpose. In addition, the UAV method was used together with a flight plan directly over LV networks. The baseline data to which these methods were referred were based on industry coordinates obtained from the following methods: geodetic direct measurements, vectorization of the basic map, or measurement with (mobile) GPS in the situational span of 1 [m]. Remote sensing techniques have an increasing range of applications for research into atmospheric phenomena occurring on Earth, including the hydrosphere, cryosphere, biosphere and lithosphere. They facilitated meeting the needs of the fields related to the research of: sustainable development, ecology and environmental protection, human impact on the environment, national security, as well as information in crisis management. [Warner 2009, Kurczyński 2008]. Remote sensing data are in the form of image information, which is obtained using devices that do not come into direct contact with the tested object. At the same time, the sources of information are pixels, which combine into unprocessed image bands from various sources. The image identification process, the source of which is information about objects, is recorded by sensors of the spectral reflection size on the wavelength function. Thanks to this, objects can be identified and combined in various contexts of object definition [Warner 2009, Drzewiecki].

\section{Assessment of usefulness of photo image content interpretation}

The information contained in photogrammetric images may have different potential for content interpretation. The basic factor affecting the way content is acquired is the electromagnetic spectrum ranges. In addition, aerial photographs should have good photographic and geometric quality, as the value of imaging usefulness is an indicator of total resolution. Acquisition of photogrammetric imaging is associated with external factors, including, among others: atmospheric conditions, direction and type of light, distribution and dispersion of light on the image plane, and the type of camera lens; as well as internal factors, for instance exposure time, resolution, contrast, image sharpness. Assessment of the usefulness and possibilities of photogrammetric imaging is an important factor affecting sufficient satisfaction of the recipient's needs [Piech 2004].

- the usefulness of photo image content interpretation is expressed by the formula (1):

$$
D=\frac{P}{C_{\max }}
$$

where:

$P$ - useful information,

$C_{\max }-$ total information, 
D - photo-interpretability coefficient (coefficient of usefulness of photo interpretation).

The coefficient of usefulness of photo interpretation is expressed by the ratio of useful information to total information, where total information is the information capacity of the photo, and its part is useful information - applied by the recipient [Smirnov 1970]. Values of useful information can be provided by objects or classes of objects with a specific contour and spatial resolution. The value of useful information is the ability to detect objects from the environment, characterized by continuity of content, e.g. building outline, or road section.

- spatial resolution

This is a scale whose image observed on the screen will change depending on the magnification used. We operate the degree of magnification by using the GSD concept of field sampling size. A related concept to GSD is GRD. Terrain resolution makes it possible to specify a measure of the resolution of an image whose terrain pixel is the size of the area imaged by a single pixel of the scanning ruler.

- NIIRS scale and level

The main task is to assess photointerpretation of the image, by determining the results of classification and identification of objects. In addition, the NIIRS system assesses the sensors used in satellite imaging systems in technical and scientific terms [Ali et al. 2016]. NIIRS consists of a ten-point scale, starting with the quality of image interpretation: 0 - lowest to 9 - highest. Scale levels are described in terms of content, for which the criterion for interpreting objects is adopted. There are 55 different criteria for a ten-point scale. Levels 1 to 9 represent six criteria for each level, while for level 0 there is only one criterion [Taejung et al. 2008]. NIIRS data values have been processed in terms of technical data.

NIIRS scale is derived from from GSD with the equation (2) of the GIQE image quality. This process predicts NIIRS values as a function, and the process factors are: image resolution, scale, image contrast, image quality processing, noise level of the NIIRS numerical scale [Ali Ahmed Mohamed et al. 2016].

$$
\begin{aligned}
\text { NIIRS }= & A_{s y s}+\left(a \log _{10} G S D_{G M}\right)+\left(b \log _{10} R E R_{G M}\right)+ \\
& +\left(0.656 \cdot H_{G M}\right)+\left(0.344 \cdot\left(\frac{G}{S N R}\right)\right)
\end{aligned}
$$

where:

$\mathrm{A}_{\text {sys }} \quad$ - coefficient for visible light (10.251) or infrared light (10.751),

a $\quad-\quad 3.32$ for $R E R \geq 0.9$ or 3.16 for $R E R \leq 0.9$,

b $\quad-1.559$ for $R E R \geq 0.9$ or 2.817 for $R E R \leq 0.9$,

$G S D_{G M}$ - geometric mean of spatial resolution,

$R E R_{G M}$ - geometric mean of relative image edge response,

$H_{G M}$ - geometric mean of height when the image edge sharpening is exceeded, 
G - noise level when sharpening image edges,

SNR - ratio determining the quantitative signal-to-noise ratio

NIIRS - NIIRS scale number [Taylor et al. 2003]

To sum up, the possibilities of image interpretation are normalized by the NIIRS assessment system, but the overall assessment should take into account the GIQE equation. The GIQE equation includes imaging parameters and allows calculations to determine the appropriate numerical scale of the NIIRS level. Appropriate NIIRS rating informs the recipient about the potential of satellite imaging.

\section{Photogrammetric techniques for obtaining digital photos}

Currently, there are three main sources for obtaining photogrammetric photos, using sensors located on: airplanes, unmanned aerial vehicles, and satellite platforms. These techniques are characterized by similar photogrammetric features, but they correspond to differences in the scale of units. Table 1 presents the features of obtaining photos by photogrammetric methods [Norman et al. 2017].

Table 1. Comparison between photogrammetric features for the UAV, aerial, and satellite techniques

\begin{tabular}{|c|c|c|c|}
\hline & UAV images & Aerial images & Satellite images \\
\hline Coverage & $\mathrm{m}-\mathrm{km}$ & $\mathrm{km}$ & $\mathrm{km}$ \\
\hline Matrix & CMOS < 100 Mpix & $\mathrm{CCD}<400$ Mpix & $\mathrm{CCD}<35000$ pix \\
\hline $\begin{array}{l}\text { Spatial resolution / } \\
\text { GSD }\end{array}$ & $\mathrm{mm}-\mathrm{cm}$ & $\mathrm{cm}-\mathrm{dm}$ & $\mathrm{dm}-\mathrm{m}$ \\
\hline \multirow{2}{*}{ Geo-location } & $\begin{array}{l}\text { Average quality GNSS/ } \\
\text { IMU }\end{array}$ & $\begin{array}{l}\text { High quality GNSS/ } \\
\text { IMU }\end{array}$ & Average quality CE90 \\
\hline & Down to a meter & Down to centimetres & $\begin{array}{l}\text { Down to several } \\
\text { metres }\end{array}$ \\
\hline Flight stability & Low-average & high & Very high \\
\hline Impact of the weather & $\begin{array}{l}\text { Highly weather- } \\
\text { dependent }\end{array}$ & Average dependence & $\begin{array}{l}\text { Virtually no } \\
\text { dependence }\end{array}$ \\
\hline $\begin{array}{l}\text { Price and costs of the } \\
\text { mission }\end{array}$ & low - average & high & Very high \\
\hline Altitude & low & Up to $<8,000$ metres & Extra terrestrial \\
\hline \multirow{2}{*}{ Flexibility } & $\begin{array}{l}\text { Mobile, some areas } \\
\text { inaccessible }\end{array}$ & $\begin{array}{l}\text { Poorly mobile, limited } \\
\text { areas }\end{array}$ & Limited mobility \\
\hline & $\begin{array}{l}\text { Independent of cloud } \\
\text { cover }\end{array}$ & $\begin{array}{l}\text { Image sensitive to } \\
\text { cloud cover }\end{array}$ & $\begin{array}{l}\text { Image sensitive to } \\
\text { cloud cover }\end{array}$ \\
\hline
\end{tabular}




\begin{tabular}{|l|l|l|l|}
\hline \multirow{2}{*}{ Flexibility } & Display on demand & $\begin{array}{l}\text { Display time depends } \\
\text { on the provider }\end{array}$ & $\begin{array}{l}\text { Display time depends } \\
\text { on the provider }\end{array}$ \\
\cline { 2 - 4 } & $\begin{array}{l}\text { Remote control - pilot } \\
\text { required }\end{array}$ & Pilot required & Service provider \\
\hline
\end{tabular}

Source: Authors' study based on: Wróbel [2008], SenFly [2015], Norman et al. [2017], Bresnahan [2011], Phase One Industrial [2017]

In addition, the pros and cons of each of the techniques presented should be estimated according to the cost and scale analysis of the specific project. An important factor is the ability to repeat the measurement at a low cost; as well as time analysis, which in the case of aerial flight can become too expensive [Norman et al. 2017]. The classification of digital images is used to assign graphic objects or a set of pixels with information that is important to the user. Information characterizes an independent class of objects, which are inherent features of the image [Campbell 2006]. Classification conducted for high-resolution images is very difficult due to the high level of image detail. Most objects do not have a defined spectral range compared to low-resolution images. In contrast, low-resolution images have noise caused by shadows, resulting in mixing of pixel values among them. The solution to the problem is not only the identification of pixels, but also additional data from sources other than the raster file. The high variety of choice of the appropriate process algorithm allows for almost unlimited control of object identification compliance, whereas it is worth remembering the limitations of changes in the configuration of the algorithm operation by the user. Certainly more advanced classification techniques will be created in the future that will increase the accuracy and correction of class matching [Karlsson 2003].

The present study details the preparatory work for detailed object detection, based on the example of the BDJ55212 station's electrical network elements. The basic source of data comes from images obtained by aerial, satellite and UAV methods. All the mentioned imaging data sets were subjected to supervised classification, and the content of the latter was analysed by samples of image pixel values and by the method of object segmentation. Then analysis was carried out in terms of the effectiveness of content detection and accuracy of position of objects, taking into account the length of the span and the direction of the columns with attributes.

\section{Research area}

The research area (Fig. 1) is located in the eastern part of the city of Jaworzno, in the Ciężkowice district. The city is located in the Silesian Region, in the southern part of Poland. The study area covers $5.20\left[\mathrm{~km}^{2}\right]$ of the land (range of the analysed supervised classification samples), including the area subjected to detailed analysis (of the BDJ55212 network elements) that will cover $0.26\left[\mathrm{~km}^{2}\right]$ of the land. 


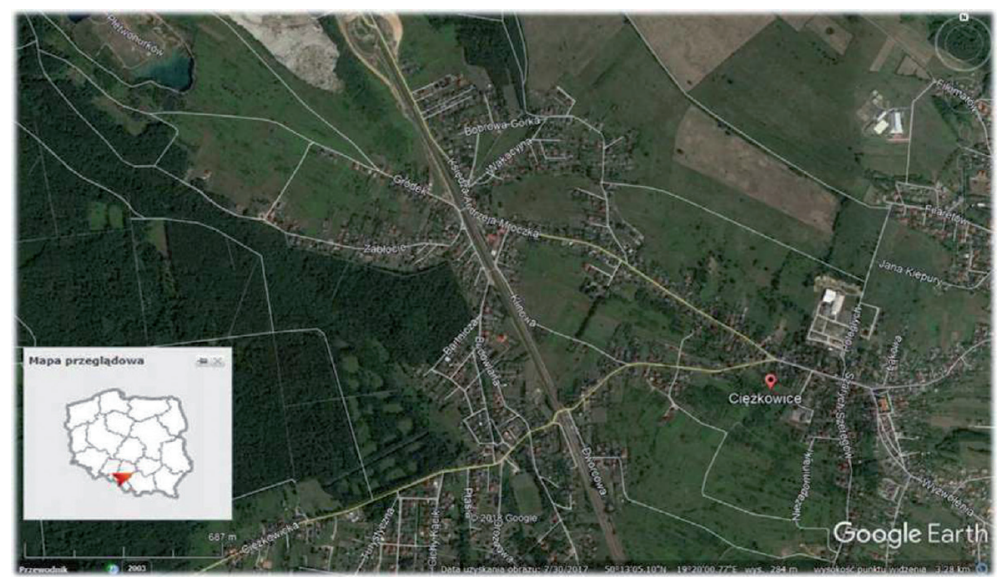

Source: Bordzań [2018]

Fig. 1. Research area - Jaworzno

\section{Small and medium format imaging}

The main goal of the study is to develop an effective method of LV network detection in maintaining a balance between data resolution and spatial coverage. Small and medium format images were used for the analysis, whereas additional characteristics are described in Table 2.

Table 2. The listing of source data and their characteristics

\begin{tabular}{|l|c|c|l|c|l|}
\hline Imagining & $\begin{array}{c}\text { Image resolution } \\
{[\mathrm{pix}]}\end{array}$ & $\begin{array}{c}\text { Field resolution } \\
{[\mathrm{m}]}\end{array}$ & Camera type & $\begin{array}{c}\text { Spatial range } \\
{\left[\mathbf{k m}^{2}\right]}\end{array}$ & $\begin{array}{c}\text { Manner } \\
\text { of acquisition }\end{array}$ \\
\hline Satellite & $7674 \times 7954$ & $0.31(\mathrm{good})$ & WorldView 3 & 5.501 & $\begin{array}{l}\text { Purchase } \\
\text { of a license }\end{array}$ \\
\hline Aerial & $8957 \times 9303$ & $0.18(\mathrm{high})$ & $\begin{array}{l}\text { UltraCamX } \\
\text { Eagle }\end{array}$ & 5.212 & $\begin{array}{l}\text { Purchase } \\
\text { of a license }\end{array}$ \\
\hline UAV & $3281 \times 4418$ & $0.01($ very high) & SONY ILCE-7R & 0.003 & Direct \\
\hline
\end{tabular}

Source: Bordzań [ 2018]

Only two of the three types of image data met the spatial coverage criteria. The UAV method is too expensive to support the entire network due to environmental conditions and equipment capabilities. The acquired data were divided into two missions (I-nN and II-SN), which were used as an additional source of information for detecting details of LV and MV networks. Other methods of obtaining images do not produce sufficient image resolution, therefore they were not combined with the UAV method. 


\section{Initial preparations}

Before proceeding to obtain photos using the UAV method, an analysis of the development area was carried out, in particular regarding the values of land elevation, occurrence of tall objects, e.g. towers, buildings, elements of the power grid, and availability of the air zone over the studied area. Then a plan for the photogrammetric flight was prepared, taking into account the range and height of the flight to ensure adequate resolution of scenes and the nature of the camera's work. In order to identify the location of aerial photographs, a photogrammetric matrix is assumed. The matrix requires direct measurement, and its course should extend between the corners of the blocks in the zones of multiple longitudinal and transverse coverage of photos [Piech 2015].

The draft flight plan (Fig. 2) for mission I involved the following assumptions:

- two series of aerial photos: 8 scenes, 4 photos per series,

- photo coverage: longitudinal - 60 [\%], transverse - 40 [\%],

- flight altitude above the ground: 50 [m],

- field resolution of $8[\mathrm{~mm} / \mathrm{pix}]$.

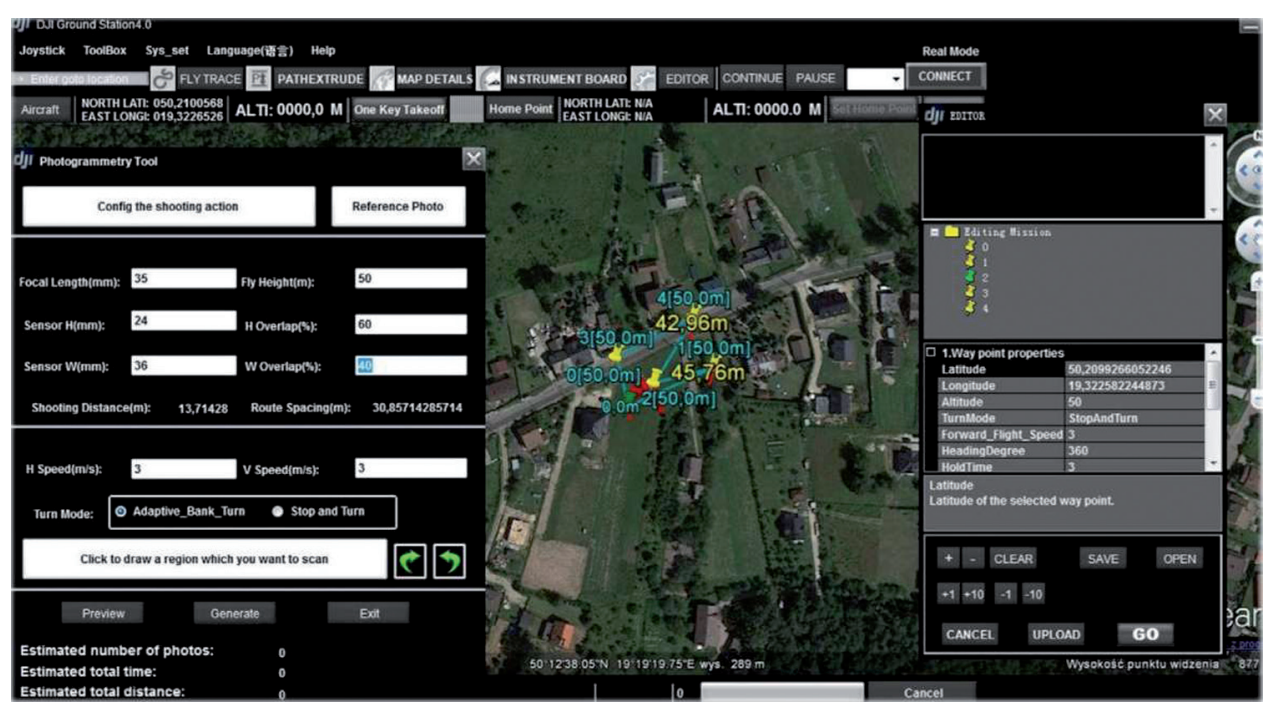

Source: Bordzań [2018]

Fig. 2. Plan of the photogrammetric flight

Mission II was conducted manually. All flight parameters were provided by the flight controller using a radio station, whereas the pilot controlled the vehicle using a remote controller. The mission included two series of scenes. In total, 24 scenes were made, 12 in one series. The location of photo points was determined during the planning phase of the flight, while the measurement and compaction of the photogrammetric matrix 
were made just before the flight. Mission I was based on 5 photo points, distributed in close proximity to subsequent scenes (Fig. 3). Points were measured by direct method, using the GPS Trimble R-7 TSC-3 satellite set.

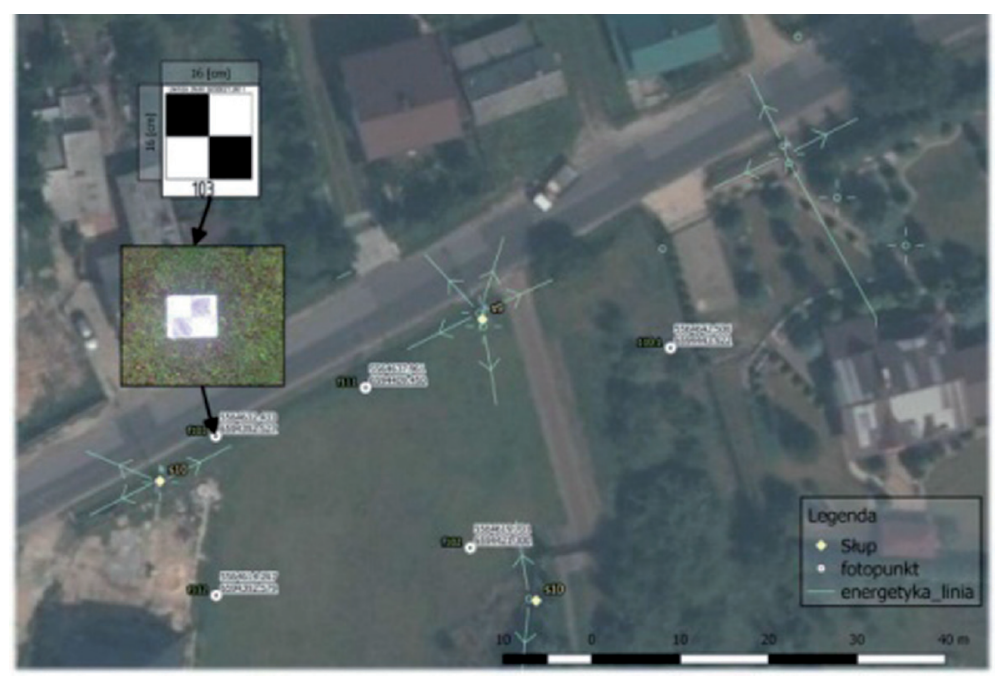

Source: Bordzań [2018]

Fig. 3. Location of photo points for the implementation of mission I; description and visualisation using the QGIS software application

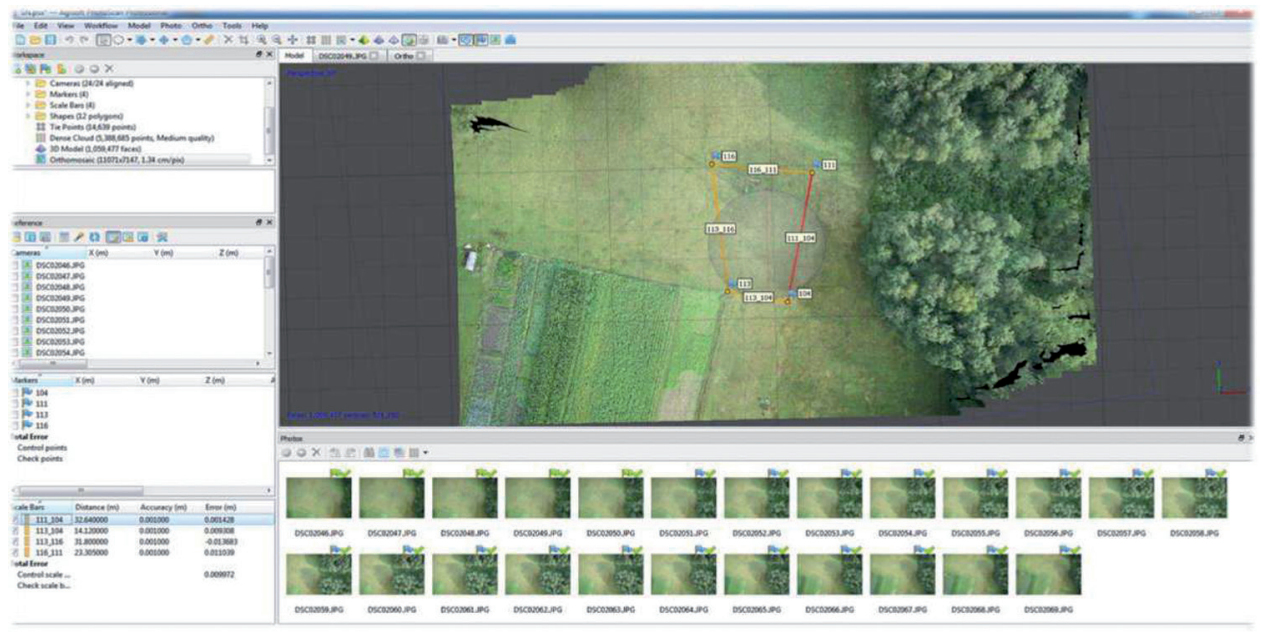

Source: Bordzań [2018]

Fig. 4. Location of photo points for the implementation of mission II, description and visualisation using the Agisoft PhotoScan software application 
Mission II was based on 4 photo points, distributed on a rectangular plan (Fig. 4) that surrounded the examined object. Photo points were measured by the traditional method, using measuring tape. In this way, the length of the shooting base was determined.

The result of the study was the editing of the orthophotomap (Fig. 5). The studies have visible defects, but nevertheless they are suitable for research purposes. Mission I had many scenes cut due to insufficient longitudinal and transverse coverage. The solution to the problem would be to increase the number of photos per series. Mission II is burdened with high distortion errors at the edges of the block, caused by insufficient number of measurement series. The solution would be to increase the number of series or lower the altitude of the flight.

a)

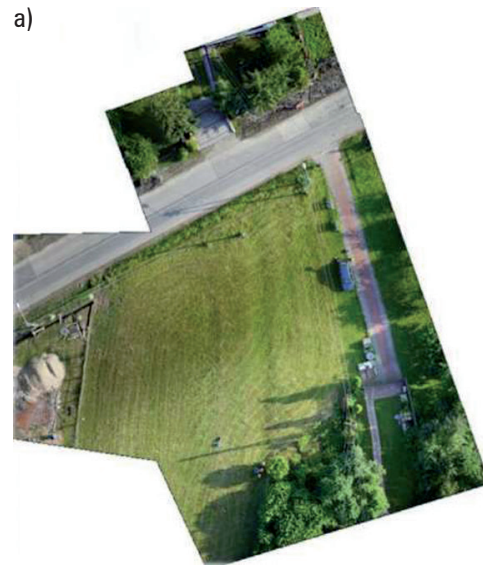

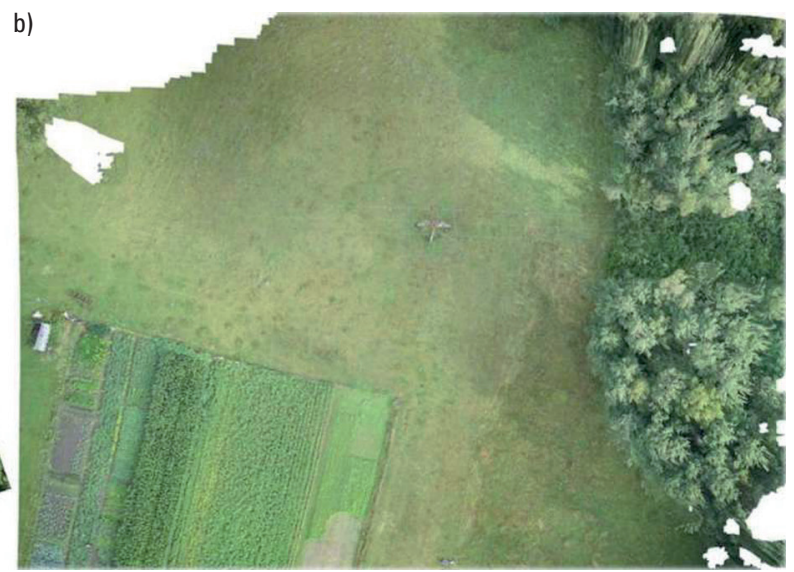

Source: Bordzań [2018]

Fig. 5. Editing of ortophotomap a) mission I LV network b) mission II SN network

\section{An introduction to supervised classification}

In order to properly implement the supervised classification process on high-resolution images, it is important to determine what types of area we are dealing with. In addition to the basic content (low vegetation, buildings, forests, arable fields, roads, water reservoirs, etc.), we may encounter atypical areas of land development (buildings and road works, waste dumps, mining or excavation areas, or other) for which an additional attribute of land development should be added. An example of that is the industrial waste landfill (Fig. 6) in the Ciężkowice district. 


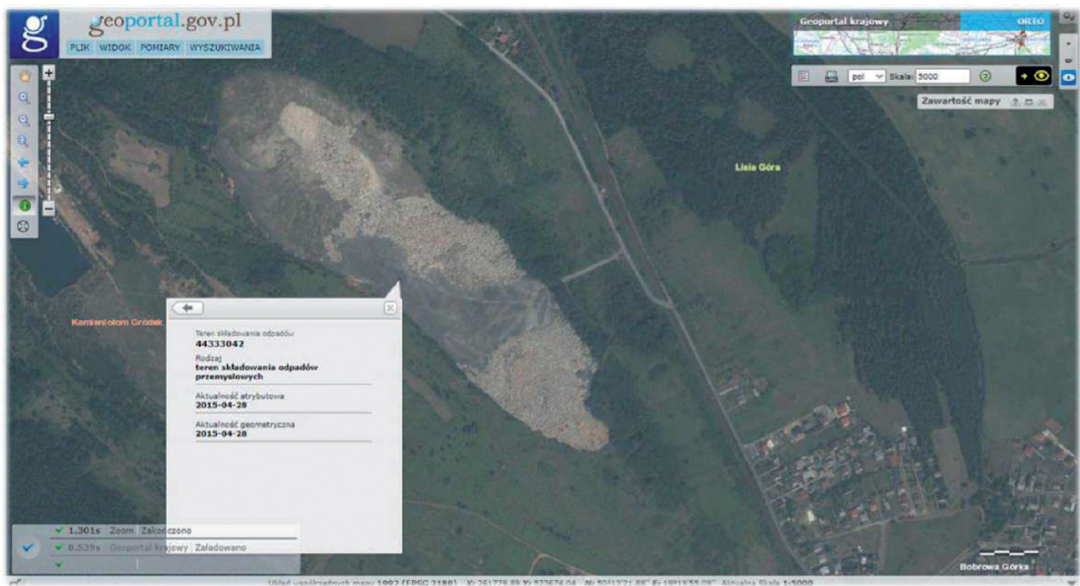

Source: geoportal.gov.pl

Fig. 6. Identification of land development based on the geoportal

\section{Introduction of training fields}

Each group (Fig. 7) of training fields should be assigned to one of the classes. Classes describe the imaging in a way that is set by the user to take away the most needed content. The number of training fields should be appropriate for the scale of the imaging, while there are no restrictions as to the shape of the training fields. It is important that the size of one training field does not overlap with extreme pixel values for the defined class and that it is not overly extensive.

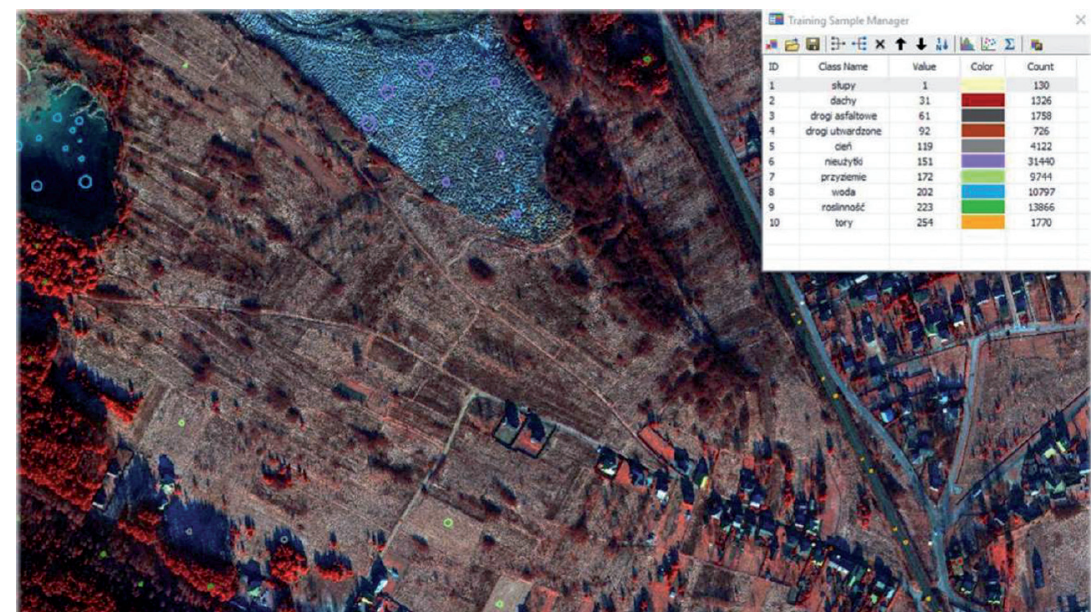

Source: Bordzań [2018]

Fig. 7. Definition of training fields for WordView-3 satellite imaging 
The study was divided into 6-10 classes of land classification. Training fields (Table 3) have been marked on the extreme and central imaging positions.

Table 3. The number of training fields in the development of supervised classification

\begin{tabular}{|c|c|c|c|}
\hline Raster & Satellite & Aerial & UAV - mission I UAV - mission II \\
\hline Number of training fields & 254 & 242 & 282.111 \\
\hline
\end{tabular}

Source: Bordzań [2018]

\section{Process of object segmentation and supervised classification, content separation}

Detection of a specific nature of the content can be subjected to analysis in various spectral ranges or through direct interference in the display of imaging. The very process of supervised classification without preliminary assumptions will not produce sufficient results. Due to the nature of the detection of concrete and steel elements, the images were developed in the following displays: aerial - CIR, satellite - CIR2, UAV - RGB. In order to compare the detection possibilities, each of the images was subjected to object segmentation, which consists in analysing and calculating the number of pixels with similar values, selected by the user. It is a process that directly interferes with the content of the display. For the purposes of the study, segmentation with a concentration of four pixels was performed. Imaging before and after object segmentation was processed using the same algorithms and training fields. The summary of results and analysis will allow us to answer the question whether the resolution of images for supervised classification is a sufficient model in the detection of power networks. The class: water and roofs has not been designated for UAV imaging, because the resultant images did not have such content. The introduction and matching of training fields other than the content of the images can contribute to errors in the allocation of classes and, as a result, it can generate noise.

\section{Data separation}

The result records are saved as raster files. Content that is not part of the power network is removed. Due to the large amount of residual noise (Fig. 8), records are converted into polygons using the "conversion tools" toolbox and the "raster to polygon" tool.

Based on direct measurements, the base positions of the towers of the power line were determined. The next operation was to determine the predictable position based on photogrammetric images. All polygons that were outside the radius of 3 meters from the tower's position are then removed. The results of the position of the towers (Fig. 9) in the centroid of the polygon constitute the basis for determining the spans of the power line between the positions of the towers. 


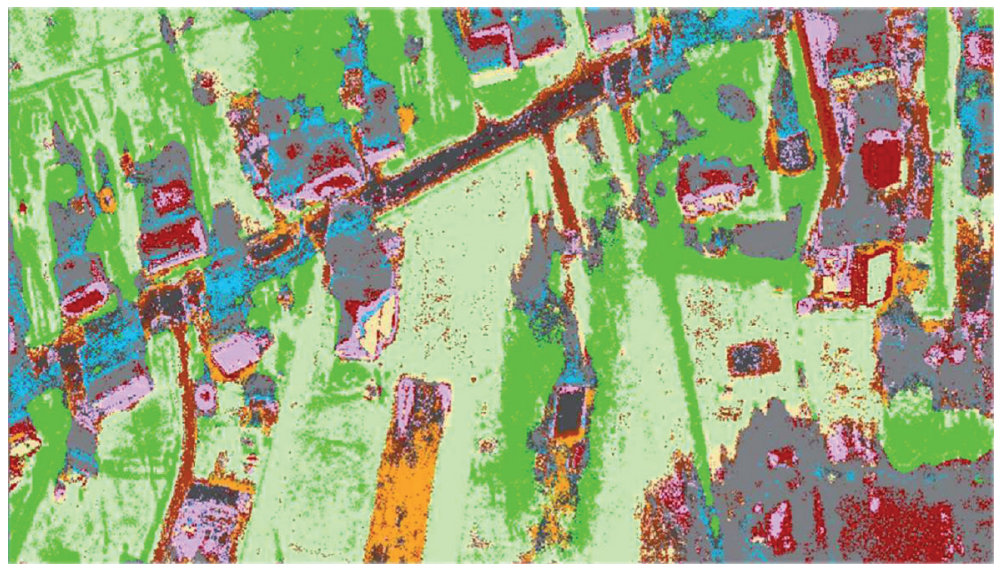

Source: Bordzań [2018]

Fig. 8. Noise generated during supervised classification, a sample developed based on RT algorithm, for the WorldView-3 imaging

a)

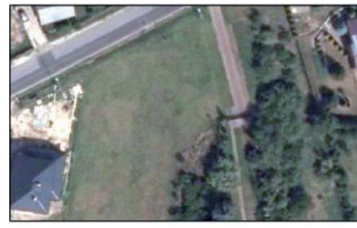

b)

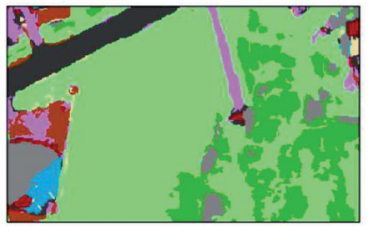

c)

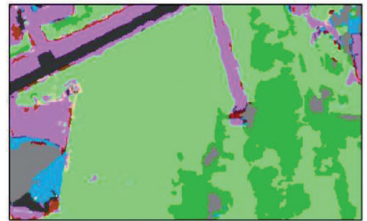

d)

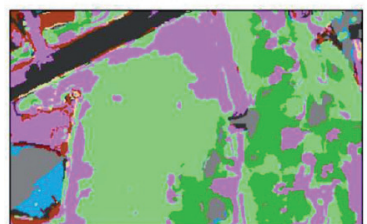

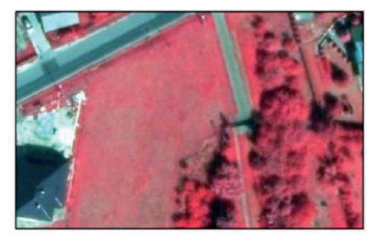
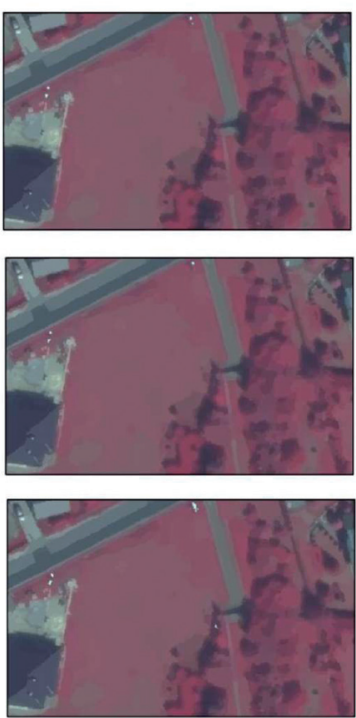

Source: Bordzań [2018]

Fig. 9. Example of data separation in a section of LV power line a) base raster, b) raster of MLC algorithm, c) raster of RT algorithm, d) raster of SVM algorithm 
For UAV studies, designated polygons constitute a different value than large-scale (aerial and satellite) imaging. The basis for the evaluation of detection methods was the value expressed by the complexity of the power network. The evaluation components include geographical features and features dedicated to electrical engineering structures. Each of the features receives a weight in the range of 0.5-2.5, where the sum of 10.0 determines complete compliance with the elements and attributes of the network in the GIS system. The power network was considered by dividing it into point elements and line elements. Point elements are the location of the power line tower and its structure (lighting fixture, surge arresters), while line elements include the length of the section and the system of wires.

\section{Determining weight of the elements of power network}

To carry out a comprehensive network inventory, we use technical documentation in combination with image data. The documents form the basis of information in the aspect of which content compliance lies. Unfortunately, some documents do not contain current data due to their limitation in relation to the actual, up-to-date condition of the network. The incompleteness of information is due to the lack of direct record into the database during network expansion or replacement of components that have malfunctioned. The basic information about the network is the exact location of its elements and the length of the section. For network inventorying, Table 4 summarizes the most important elements along with a description of the weights for each of them.

Table 4. Assigning weights to specific elements of the power network and its values

\begin{tabular}{|l|c|c|c|c|}
\hline $\begin{array}{c}\text { Feature } \\
\text { of the element }\end{array}$ & Location & $\begin{array}{c}\text { Type } \\
\text { of tower }\end{array}$ & $\begin{array}{c}\text { Lighting } \\
\text { fixture }\end{array}$ & Direction \\
\hline Point & 2.5 & 1.5 & 0.5 & 0.5 \\
\hline Feature of the element & $\begin{array}{c}\text { Span } \\
\text { length }\end{array}$ & $\begin{array}{c}\text { Power } \\
\text { connection }\end{array}$ & $\begin{array}{c}\text { Type } \\
\text { of section }\end{array}$ & $\begin{array}{c}\text { Additional } \\
\text { elements }\end{array}$ \\
\hline Line & 2.5 & 1.5 & 0.5 & 0.5 \\
\hline
\end{tabular}

Source: Bordzań [2018]

\section{Assessment of methods for detecting power network elements}

The following images were used in the development of the study in the area of the Ciężkowice district:

a. Aerial and satellite images in the entire LV BDJ55212 network.

b. UAV mission I for a small part of the LV BDJ55212 network.

c. UAV mission II for part of the MV facility. 
The BDJ55212 network consists of:

- Overhead LV station - BDJ55212.

- Two LV circuits designated as I and II. The network consists of 30 towers, circuit I (2 singular and 4 divider), circuit II (14 singular and 10 divider).

- 21 lighting fixtures along the road.

- Overhead sections of the main network, a total of 995 [m], (6 spans of circuit I, 24 spans of circuit II).

\section{Aerial study}

Unfortunately, no single algorithm of supervised classification produced sufficient results that would allow the development of the entire network. Table 5 summarizes the detection results for individual algorithms.

Table 5. Detection results for point and line elements of the LV network - aerial method

\begin{tabular}{|l|r|r|r|r|r|r|}
\hline \multicolumn{7}{|c|}{ Aerial study } \\
\hline \multicolumn{1}{|c|}{ Raster } & \multicolumn{2}{c|}{ CIR } & \multicolumn{2}{c|}{ CIR + object segmentation } \\
\hline Algorithm & MLC & SVM & RT & MLC & SVM & RT \\
\hline Base towers [no. of items] & 30 & 30 & 30 & 30 & 30 & 30 \\
\hline Base towers detection [no. of items] & 13 & 21 & 5 & 13 & 20 & 8 \\
\hline Percentage share [\%] & 43 & 70 & 17 & 43 & 67 & 27 \\
\hline Singular towers [no. of items] & 16 & 16 & 16 & 16 & 16 & 16 \\
\hline Singular towers detection [no. of items] & 13 & 18 & 4 & 11 & 17 & 8 \\
\hline Percentage share [\%] & 81 & 113 & 25 & 69 & 106 & 50 \\
\hline Divider towers [no. of items] & 14 & 14 & 14 & 14 & 14 & 14 \\
\hline Divider towers detection [no. of items] & 0 & 3 & 1 & 2 & 3 & 0 \\
\hline Percentage share [\%] & 0 & 21 & 7 & 14 & 21 & 0 \\
\hline Lighting fixture [no. of items] & 21 & 21 & 21 & 21 & 21 & 21 \\
\hline Lighting fixture detection [no. of items] & 12 & 15 & 12 & 14 & 14 & 14 \\
\hline Main LV power grid [m] & 995 & 995 & 995 & 995 & 995 & 995 \\
\hline Main LV power grid detection [m] & 80 & 426 & 38 & 72 & 224 & 0 \\
\hline Percentage share [\%] & 8 & 43 & 4 & 7 & 23 & 0 \\
\hline
\end{tabular}

Source: Bordzań [2018]

Table 5 shows that the best results were obtained by the SVM algorithm based on the CIR raster. The algorithm was effective in point analysis: 70 [\%] tower detection, 71 
[\%] lighting fixture detection, 21 [\%] tower type detection. In the linear analysis, on the other hand, the SVM algorithm achieved the highest value of 43 [\%] efficiency for LV segments. The worst results in point and line analysis are produced by the RT algorithm based on the CIR raster. Due to low efficiency, all algorithm results were used as single content to supplement the network attributes. Figure 10 shows that the base elements are not completely covered, which testifies to the relatively low feasibility of performing such processes solely on the basis of aerial imaging.

Weight assessment (Table 6) confirmed poor results (Table 5) from individual algorithm samples. It is worth noting that detection of lighting fixtures turned out to be very effective, as it achieved up to 90 [\%] efficiency. Unfortunately, aerial imaging has too insufficient resolution to detect: power connection, section type and other networks. As illustrated with the example of classification of an aerial image raster, it turned out that object segmentation did not improve the detection of objects.

Table 6. Weighted assessment of the point and line elements' detection in the LV network - by aerial method

\begin{tabular}{|c|c|c|c|}
\hline Assessment & $\begin{array}{l}\text { Maximum rating } \\
\text { [points] }\end{array}$ & $\begin{array}{c}\text { Result } \\
\text { [points] }\end{array}$ & $\begin{array}{c}\text { Efficiency } \\
{[\%]}\end{array}$ \\
\hline Feature of the element & \multicolumn{3}{|c|}{ Point } \\
\hline Location & 2.5 & 1.83 & 73 \\
\hline Type of tower & 1.5 & 0.95 & 63 \\
\hline Lighting fixture & 0.5 & 0.45 & 90 \\
\hline Direction & 0.5 & 0.18 & 36 \\
\hline Feature of the element & \multicolumn{3}{|c|}{ Line } \\
\hline Length of LV network & 2.5 & 1.46 & 59 \\
\hline Power connection & 1.5 & 0 & 0 \\
\hline Type of section & 0.5 & 0 & 0 \\
\hline Additional elements & 0.5 & 0 & 0 \\
\hline Total rating & 10.0 & 4.87 & 49 \\
\hline
\end{tabular}

Rating scale:

10.0-9.0 Content very highly complete

8.9-7.5 Content highly complete

7.4-5.5 Average completeness of the content

5.4-3.0 Low completeness of the content

2.9-0.0 Negligible completeness of the content

Source: Bordzań [2018] 


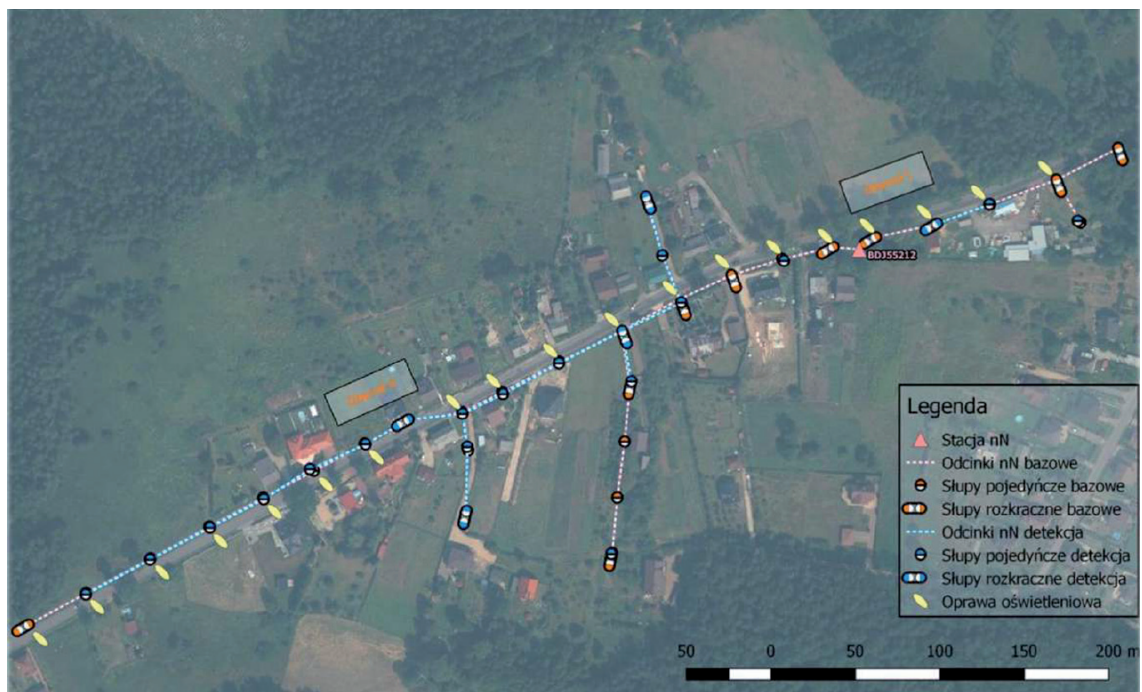

Source: Bordzań [2018]

Fig. 10. Results of the detection of aerial imaging based on supervised classification, presented in QGIS software application

\section{Satellite study}

Similar to aerial study, no supervised classification algorithm produced sufficient results that would facilitate developing the entire network. Below (Table 7) are the results of detection for individual algorithms.

Table 7. Detection results for point and line elements of the LV network - satellite method

\begin{tabular}{|l|r|r|r|r|r|c|}
\hline \multicolumn{7}{|c|}{ Satellite method } \\
\hline \multicolumn{1}{|c|}{ Raster } & \multicolumn{3}{c|}{ CIR } & \multicolumn{2}{c|}{ CIR + object segmentation } \\
\hline Algorithm & MLC & SVM & RT & MLC & SVM & RT \\
\hline Base towers [no. of items] & 30 & 30 & 30 & 30 & 30 & 30 \\
\hline Base towers detection [no. of items] & 16 & 9 & 0 & 22 & 12 & 5 \\
\hline Percentage share [\%] & 53 & 30 & 0 & 73 & 40 & 17 \\
\hline Singular towers [no. of items] & 16 & 16 & 16 & 16 & 16 & 16 \\
\hline Singular towers detection [no. of items] & 13 & 7 & 0 & 18 & 17 & 3 \\
\hline Percentage share [\%] & 81 & 44 & 0 & 113 & 106 & 19 \\
\hline
\end{tabular}




\begin{tabular}{|l|r|r|r|r|c|c|}
\hline Divider towers [no. of items] & 14 & 14 & 14 & 14 & 14 & 14 \\
\hline Divider towers detection [no. of items] & 3 & 2 & 0 & 4 & 3 & 2 \\
\hline Percentage share [\%] & 21 & 14 & 0 & 29 & 21 & 14 \\
\hline Lighting fixture [no. of items] & 21 & 21 & 21 & 21 & 21 & 21 \\
\hline Lighting fixture detection [no. of items] & 2 & 3 & 1 & 5 & 2 & 1 \\
\hline Main LV power grid [m] & 995 & 995 & 995 & 995 & 995 & 995 \\
\hline Main LV power grid detection [m] & 366 & 86 & 0 & 107 & 64 & 0 \\
\hline Percentage share [\%] & 37 & 9 & 0 & 11 & 6 & 0 \\
\hline
\end{tabular}

Source: Bordzań [2018]

It can be seen in Table 7 that the best results were obtained by applying the MLC algorithm based on the CIR2 raster with object segmentation. The algorithm was effective in point analysis: 73 [\%] tower detection, 24 [\%] lighting fixture detection, 29 [\%] tower type detection. However, in the line analysis, the CIR2 algorithm achieved the highest value of 37 [\%] efficiency for LV segments. Due to low efficiency, all algorithm results were used as single content to supplement the network attributes. In Figure 11 it can be observed that the base elements are not completely covered, which suggests the low feasibility of performing such processes based solely on satellite imaging.

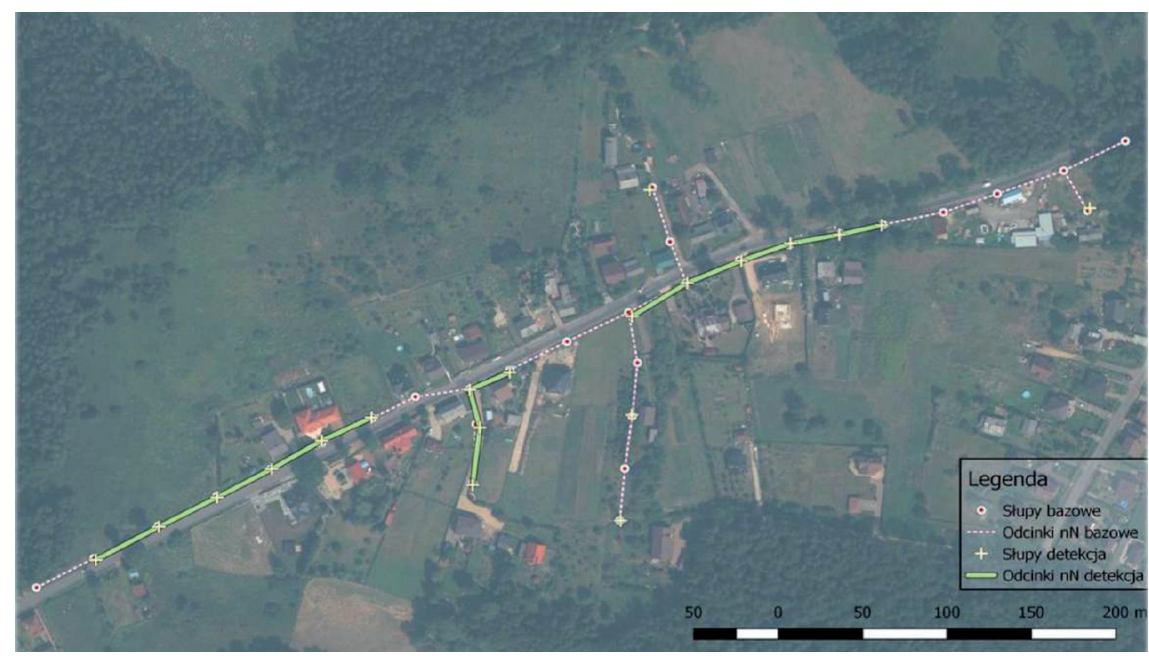

Source: Bordzań [2018]

Fig. 11. Results of the detection of satellite imaging based on supervised classification, presented in QGIS software application 
Weighted assessment (Table 8) confirmed poor results (Table 7) from individual algorithm samples.

Table 8. Weighted assessment of the point and line elements' detection in the LV network - by satellite method

\begin{tabular}{|l|c|c|c|}
\hline \multicolumn{1}{|c|}{ Assessment } & $\begin{array}{c}\text { Maximum rating } \\
\text { [points] }\end{array}$ & $\begin{array}{c}\text { Result } \\
\text { [points] }\end{array}$ & $\begin{array}{c}\text { Efficiency } \\
{[\%]}\end{array}$ \\
\hline Feature of the element & \multicolumn{3}{|c|}{ Point } \\
\hline Location & 2.5 & 1.58 & 63 \\
\hline Type of tower & 1.5 & 0.85 & 57 \\
\hline Lighting fixture & 0.5 & 0.29 & 36 \\
\hline Direction & 0.5 & 0.18 & 44 \\
\hline Feature of the element & & Line & 0 \\
\hline Length of LV network & 2.5 & 0,89 & 0 \\
\hline Power connection & 1.5 & 0 & 0 \\
\hline Type of section & 0.5 & 0 & 38 \\
\hline Additional elements & 0.5 & 3.79 & \\
\hline Total rating & 10.0 & & 0 \\
\hline
\end{tabular}

Rating scale:

10.0-9.0 Content very highly complete

8.9-7.5 Content highly complete

7.4-5.5 Average completeness of the content

5.4-3.0 Low completeness of the content

2.9-0.0 Negligible completeness of the content

Source: Bordzań [2018]

Unfortunately, satellite imaging has too low resolution for detecting sections: power connections, section type and other networks. As illustrated with the example of satellite raster classification, it is worth noting that object segmentation positively influenced the improvement of object detection - by four percentage points.

\section{UAV development - mission I}

Compared to previous studies, in mission I the research area covers only a small part of the BDJ55212 network. The elements of the network part are: 2 singular towers and one divider tower, 2 lighting fittings, 5 sections of the main LV network, 4 power connections to customers. 
Table 9 shows that the best results were achieved by the RT algorithm based on the RGB raster with object segmentation. The algorithm was effective in detecting: 100 [\%] towers, 100 [\%] lighting fixtures, 97 [\%] main LV network and 53 [\%] power connections.

Table 9. Detection results for point and line elements of the LV network - UAV method

\begin{tabular}{|c|c|c|c|c|c|c|}
\hline \multicolumn{7}{|c|}{ UAV method } \\
\hline Raster & \multicolumn{3}{|c|}{ CIR } & \multicolumn{3}{|c|}{ CIR + object segmentation } \\
\hline Algorithm & MLC & SVM & RT & MLC & SVM & RT \\
\hline Base towers [no. of items] & 3 & 3 & 3 & 3 & 3 & 3 \\
\hline $\begin{array}{l}\text { Base towers detection } \\
\text { [no. of items] }\end{array}$ & 2 & 3 & 3 & 3 & 3 & 3 \\
\hline Percentage share $[\%]$ & 67 & 100 & 100 & 100 & 100 & 100 \\
\hline Singular towers [no. of items] & 2 & 2 & 2 & 2 & 2 & 2 \\
\hline Singular towers detection [no. of items] & 2 & 3 & 3 & 3 & 2 & 2 \\
\hline Percentage share $[\%]$ & 100 & 150 & 150 & 150 & 100 & 100 \\
\hline Divider towers [no. of items] & 1 & 1 & 1 & 1 & 1 & 1 \\
\hline Divider towers [no. of items] & 0 & 0 & 0 & 0 & 1 & 1 \\
\hline Percentage share $[\%]$ & 0 & 0 & 0 & 0 & 100 & 100 \\
\hline Lighting fixture [no. of items] & 2 & 2 & 2 & 2 & 2 & 2 \\
\hline Lighting fixture detection [no. of items] & 2 & 2 & 2 & 2 & 2 & 2 \\
\hline Main LV power grid [m] & 102 & 102 & 102 & 102 & 102 & 102 \\
\hline Percentage share [\%] & 100 & 100 & 100 & 100 & 100 & 100 \\
\hline
\end{tabular}

Source: Bordzań [2018]

It can be seen in Figure 12 that all LV network elements are detected. However, not all components have satisfactory continuity - this applies to power connections in particular. Weighted assessment (Table 9) confirmed high quality results (Table 8) from individual algorithm samples. UAV imaging has sufficient resolution to detect the main elements of the LV network. For elements such as power connection to the customer, the effect is ambiguous because the sections are interrupted. Based on the example of the UAV raster classification in mission I, it is worth noting that object segmentation improved object detection by three percentage points. 


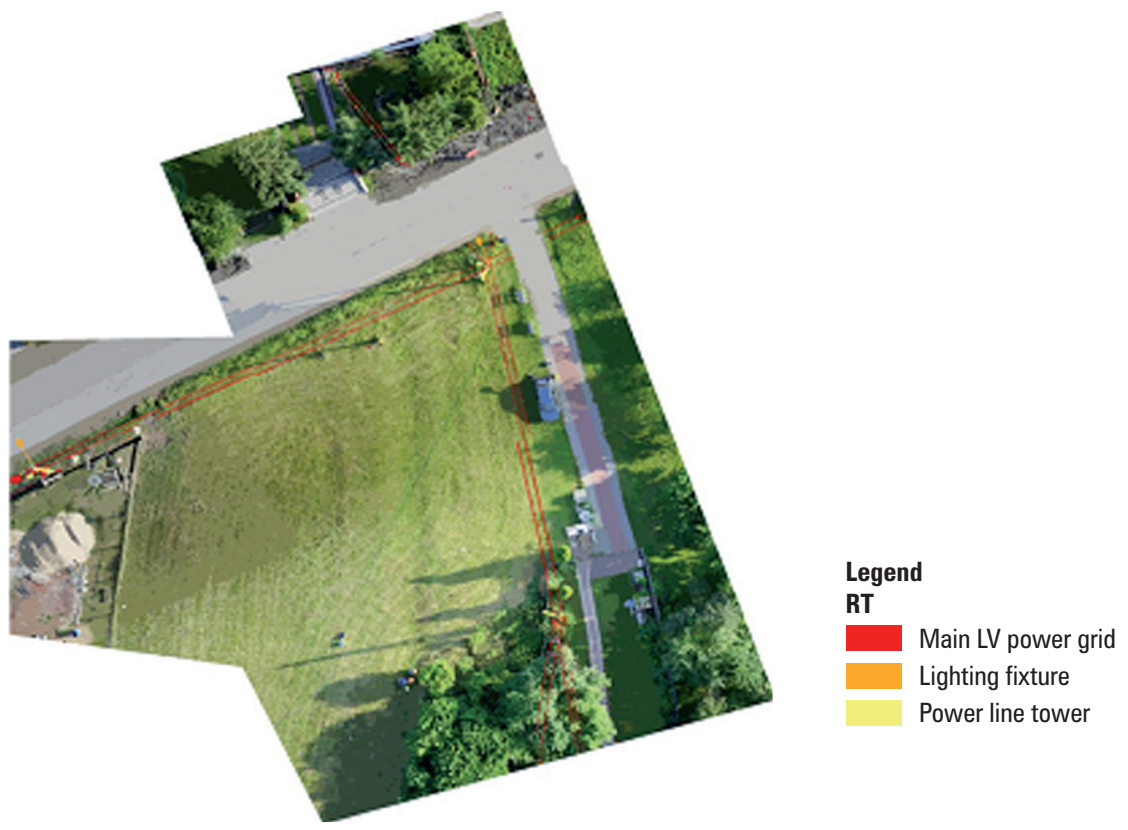

Source: Bordzań [2018]

Fig. 12. Results of the supervised classification for RT, RGB raster, object segmentation performed using the ArcGIS software application

\section{UAV development - mission II}

The development of mission II differs from mission I above all in the elements of the network. The research area includes part of the MV network. The network elements are: one divider tower, 3 pieces of voltage limiters, and 3 sections of the main MV network.

Table 10. Detection results for point and line elements of the MV network - UAV method

\begin{tabular}{|l|r|r|r|r|r|r|}
\hline \multicolumn{1}{|c|}{ Raster } & \multicolumn{3}{c|}{ RGB } & \multicolumn{3}{c|}{ RGB + object segmentation } \\
\hline Algorithm & MLC & SVM & RT & MLC & SVM & RT \\
\hline Divider tower [no. of items] & 1 & 1 & 1 & 1 & 1 & 1 \\
\hline Divider tower detection [no. of items] & 1 & 1 & 1 & 1 & 1 & 1 \\
\hline Percentage share [\%] & 100 & 100 & 100 & 100 & 100 & 100 \\
\hline Voltage limiters [no. of items] & 5 & 5 & 5 & 5 & 5 & 5 \\
\hline Voltage limiters detection [no. of items] & 5 & 3 & 4 & 5 & 3 & 4 \\
\hline
\end{tabular}




\begin{tabular}{|l|c|c|c|c|c|c|}
\hline Percentage share [\%] & 100 & 60 & 80 & 100 & 60 & 80 \\
\hline Main MV power grid [m] & 160 & 160 & 160 & 160 & 160 & 160 \\
\hline Main MV power grid detection [m] & 142 & 142 & 142 & 126 & 98 & 122 \\
\hline Percentage share [\%] & 89 & 89 & 89 & 79 & 96 & 76 \\
\hline
\end{tabular}

Source: Bordzań [2018]

Table 10 demonstrates that the best quality results were achieved by the MLC algorithm based on the RGB raster. The algorithm has been successful in detecting: 100 [\%] tower, 100 [\%] voltage limiters, 89 [\%] MV main power grid.

It can be seen in Figure 13 that all MV network elements are detected. On the other hand, elements of the MV main power grid do not show complete continuity.

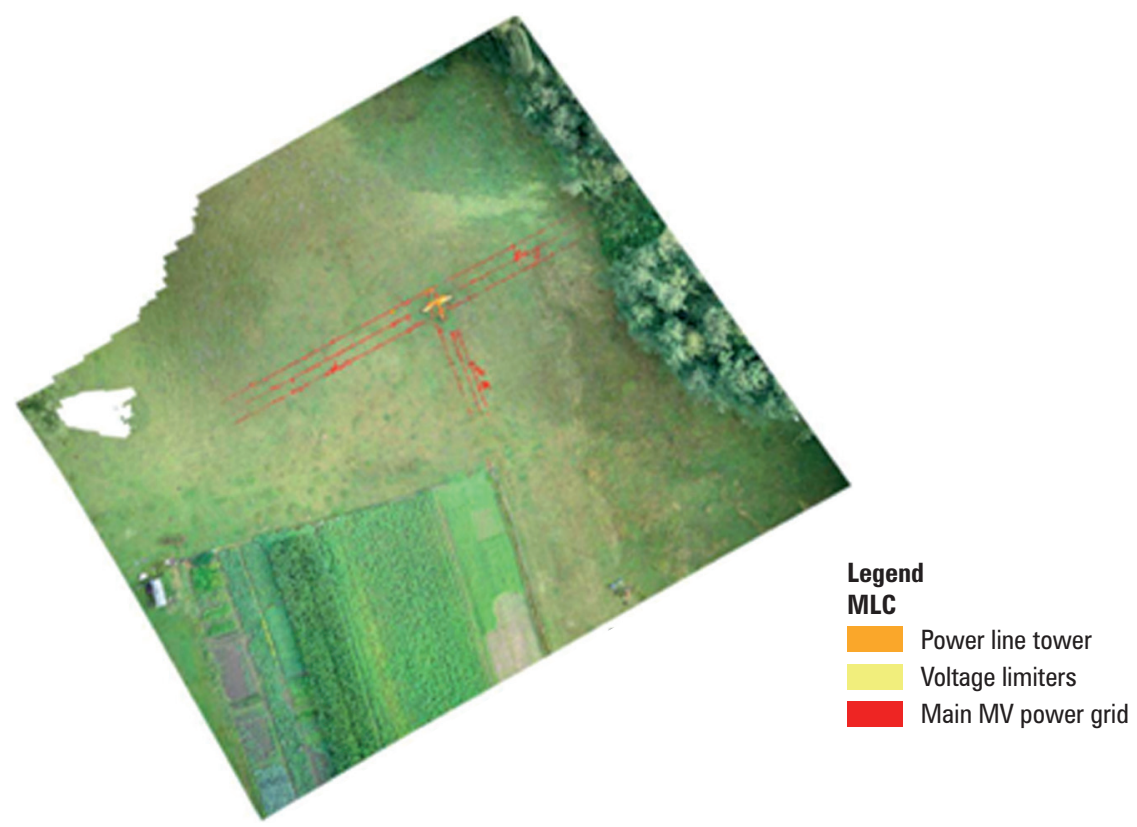

Source: Piotr Bordzań

Fig. 13. Results of the supervised classification for MLC algorithm, performed using the ArcGIS software application

Weighted assessment (Table 11) confirmed the high quality results (Table 10) of individual algorithm samples. UAV imaging has sufficient resolution enabling to detect the main elements of the MV network. The frame of the supporting structure was detected only in the middle of the arm, and the result is ambiguous. 
Table 11. Weighted assessment of the point and line elements' detection in the MV network by UAV method

\begin{tabular}{|l|c|c|c|}
\hline \multicolumn{1}{|c|}{ Assessment } & $\begin{array}{c}\text { Maximum rating } \\
\text { [points] }\end{array}$ & $\begin{array}{c}\text { Result } \\
\text { [points] }\end{array}$ & $\begin{array}{c}\text { Efficiency } \\
{[\%]}\end{array}$ \\
\hline Feature of the element & \multicolumn{3}{|c|}{ Point } \\
\hline Location & 2.5 & 2.5 & 100 \\
\hline Type of tower & 1.5 & 1.5 & 100 \\
\hline Voltage limiters & 0.5 & 0.5 & 100 \\
\hline Direction & 0.5 & 0.5 & 100 \\
\hline Feature of the element & & Line & 89 \\
\hline Length of the MV power grid & 2.5 & 2.23 & 100 \\
\hline Type of section & 0.5 & 0.5 & 50 \\
\hline Additional elements & 0.5 & 0.25 & 94 \\
\hline Total rating & 8.5 & 7.98 & \\
\hline
\end{tabular}

Rating scale:

8.5-7.0 Content very highly complete

6.9-5.5 Content highly complete

5.4-3.5 Average completeness of the content

3.4-1.0 Average completeness of the content

0.9-0.0 Negligible completeness of the content

Source: Bordzań [2018]

As illustrated with the example of UAV raster classification mission II, it is worth noting that object segmentation adversely affected the detection of objects - by seventeen percentage points.

\section{Conclusions from study results}

The purpose of this study was to determine the resolution capabilities of imaging for various photogrammetric studies using supervised classification techniques. The substantive content was the LV and MV energy network on a local scale. The examined content consists of various elements, which means that in-depth analysis raises a number of questions.

The most important question is whether photogrammetric methods are able to effectively describe the course of the power network along with all elements of the network and whether these methods are cost-effective. The answer is affirmative, but only for the UAV technique. The full content of the network is reflected in the samples 
from mission I and II. The missing content resulted only from the insufficient number of flight series. In addition, some margin of error had to be assumed, because neither mission was carried out for the full network coverage, but they were conducted for local areas only. Unfortunately, the resolution in the satellite and aerial methods turned out to be insufficient for full detection of the network and its elements. The content that was obtained with 90 [\%] efficiency is the lighting fixtures for the aerial study. Unfortunately, this is the only such high result in the analysis of all content. I assess both methods at poor in terms of content completeness. The reason for the aerial method advantage is the greater imaging resolution, but the 11 [\%] higher score does not make a significant difference in terms of efficiency.

I will only mention that the satellite scene used here is five times $\left(25\left[\mathrm{~km}^{2}\right]\right)$ larger than the aerial scene. In addition, satellite studies have one more basic advantage: they can be updated several times a year, and the cost is only the service fee. The field for operational activities is the software applications dedicated to photogrammetric studies. The complexity of the software application and tools in choosing optimal solutions is also a factor that could affect the results of the study.

The chosen technique of supervised classification along with object segmentation has been widely used and studied in photogrammetry for many years. It is an important Source of obtaining information based on photogrammetric data. There is also another research technique involving the creation of a complex architecture of artificial neural networks for the detection of photogrammetric imaging. This technique is fairly innovative, and the first scientific publications present encouraging results of experiments. The availability of such tools in the form of prototypes on commercial platforms is too expensive today. It is possible that the imaging results presented in this paper, which have not been sufficiently effective, may achieve better results using another detection method. Therefore, it might be worth repeating the study and compare it with further techniques in order to achieve better results.

\section{References}

Ali A.M., Elthamy F., Salama I.G. 2016. Estimation of NIIRS, for High Resolution Satellite Images, Using the Simplified GIQE, IJIRCCE, ISO:3297, 4, 5 May, 8403-8404.

Bareth G., Zarco-Tejada P.J., Atzberger C., Thenkabail Prased S. 2015. Intercomparison of UAV, Aircraft and Satellite Remote Sensing Platforms for Precision Viticulture, Article, remote sensing: 7, 2971-2990. DOI:10.3390/RS70302971, 2971-2973.

Bresnahan P.C. 2011. Geolocation Accuracy Evaluations of WorldView-1 and WorldView-2.

Cambell J.B., Wynne R.H. 2011. Introduction to Remote Sensing, 5. The Guildor Press, 31-33, 335-337.

Dąbrowski R., Orych A., Walczykowski P. 2010. Ocena możliwości wykorzystania wysokorozdzielczych zobrazowań satelitarnych w rozpoznaniu obrazowym. Archiwum Fotogrametrii, Kartografii i Teledetekcji, 21. Wydawnictwo PW, Warszawa, 75-85.

Drzewiecki W. Teledetekcja w skrócie. Kraków, dydaktyka, AGH.

Karlsson A. 2003. Classification of high resolution satellite images. Laboratory of Geographic Information System, Switzerland, August, 3-5, 38-39. 
Kurczyński Z. 2008. Pozyskiwanie danych obrazowych w świetle XXI Kongresu MTFIT w Pekinie. Archiwum Fotogrametrii, Kartografii i Teledetekcji, 18a. Wydawnictwo PW, Warszawa, 333-342.

Piech I. 2004. Dokładność identyfikacji różnego typu szczegółów przy wykorzystaniu stacji cyfrowej. Archiwum Fotogrametrii, Kartografii i Teledetekcji, 15, Kraków, 121-122.

Piech I. 2015. Prezentacja: plan nalotu, praca w programie Agisoft Photoscan. Materiały dydaktyczne. Kraków.

Smirnov L.J. 1970. Teoretyczne podstawy interpretacji, przekład z języka ros. A. Ciołkosz, A. Kęsik. Warszawa.

Taejung K., Hyunsuk K., HeeSeob K. 2008. Image-based estimation and validation of NIIRS for high resolution satellite images. IRARS Committee, 30 April, 1-4.

Taylor S.J., Cordes B., Osofsky S., Domnich A. 2003. Process for the development of image quality metrics for underwater electro-optic sensors. DOI: 10.1109/OCEANS.2002.1192105, 29 April 2003.

Warner A.T., Nellis M.D., Foody M.G. 2009. The Sage Handbook of Remote Sensing, 3-10, 411-414.

Wróbel A. Teledetekcja, Kraków, dydaktyka, AGH.

Dr inż. Izabela Piech

Uniwersytet Rolniczy w Krakowie

Katedra Geodezji Rolnej, Katastru i Fotogrametrii

ul. Balicka 253a, 30-198 Kraków

e-mail: rmpiech@cyf-kr.edu.pl

ORCID: 0000-0002-6710-4387

Dr inż. Tadeusz Żaba

Politechnika Krakowska

Katedra Wodociągów, Kanalizacji i Monitoringu Środowiska

ul. Warszawska 24, Kraków

e-mail: tadeusz.zaba@interia.pl

ORCID: 0000-0002-0967-164X

Piotr Bordzoń

Uniwersytet Rolniczy w Krakowie

Wydział Inżynierii Środowiska i Geodezji

(absolwent - graduate) 